\title{
Simulasi Pengaruh Jarak Saddle Berbahan SA 516 Gr.70 pada Bejana Tekan Horizontal Menggunakan Software Autodesk Inventor 2019
}

\author{
${ }^{\text {a}}$ Krisdiyanto \\ ${ }^{\text {a }}$ Program Studi Teknik Mesin, Fakultas Teknik, Universitas Muhammadiyah Yogyakarta \\ Jl. Brawijaya, Kasihan, Bantul, Yogyakarta 55183 \\ e-mail: krisdiyanto@umy.ac.id ${ }^{\mathrm{a}}$
}

\begin{abstract}
Pressure vessel is a complex structure. Pressure vessel is designed to resist internal pressure loads, temperature loads, external loads, etc. Horizontal pressure vessel is a type of pressure vessel. Horizontal pressure vessel is supported by two saddles. Saddle is used to hold loads from pressure vessel. Length variations saddle and tangent pressure vessel is affected to stress and displacement. Maximum stress values of pressure vessel should be considered so the failure of structure can be decreased. This research aims to review the effect length variations saddle and tangent pressure vessel to maximum stress and displacement.
\end{abstract}

Keywords: pressure vessel, saddle, tangent, finite element

\section{Pendahuluan}

Bejana tekan horisontal pada industri merupakan suatu struktur yang komplek dengan berbagai bentuk yang dibutuhkan untuk dapat bekerja pada kondisi beban tinggi yang berasal gaya di luar struktur, temperatur, tekanan internal, dan lain-lain [1]. Bejana tekan berbentuk silinder dipakai pada industri pengolahan, pembangkit, minyak dan gas untuk menampung gas atau cairan [5]. Kode yang digunakan dalam desain bejana tekan harus konsisten [4]. Bejana tekan horizontal yang berisi gas atau cairan ditopang oleh dua saddle [2]. Beban bejana tekan silinder yang ditopang oleh dua saddle akan terdistribusi pada kedua penopang tersebut [4]. Beban pada bejana tekan mempengaruhi nilai tegangan pada struktur tersebut. Nilai tegangan yang terjadi pada struktur bejana tekan perlu diketahui agar kemungkinan kegagalan desain bejana tekan dapat berkurang. Perbandingan jarak saddle dengan radius shell bejana tekan mempengaruhi nilai tegangan pada struktur bejana tekan [1]. Analisis finite element dapat digunakan untuk menyelesaikan equations untuk tegangan pada dinding material [3]. Penelitian ini bertujuan mengkaji pengaruh jarak saddle dengan tangent terhadap distribusi tegangan pada bejana tekan dengan metode finite element.

\section{MetOde}

Metode yang digunakan dalam penelitian ini yaitu membandingkan tegangan maksimum yang terdistribusi pada bejana tekan horizontal. Variabel yang digunakan dalam penelitian ini yaitu jarak antara saddle dengan tangent bejana tekan.

Bejana tekan pada penelitian ini berfungsi sebagai knock out drum dengan storage yang berisi hidrokarbon dengan fasa berupa gas dan cairan dengan densitas 45,32 lb/ft3. Data desain pada penelitian ini terdapat pada Tabel 2.1. Variasi pengujian terdapat pada Tabel 2.2. Bejana tekan pada penelitian ini didesain menggunakan ASME Boiler and Pressure Vessel Code Division I yang berjudul Rules for Construction of Pressure Vessels. Material yang digunakan merupakan SA $516 \mathrm{Gr}$. 70. Spesifikasi material tersebut terdapat pada Tabel 2.3. 
Geometri pada penelitian ini dibuat menggunakan Software Autodesk Inventor 2019. Salah satu geometri yang digunakan penelitian ini terdapat pada Gambar 2.1. Contoh mesh geometry pada penelitian ini terdapat pada Gambar 2.2.

Tabel 2.1 Data desain

\begin{tabular}{clc}
\hline No & Deskripsi & Nilai \\
\hline 1 & Inside diameter & $2500 \mathrm{~mm}$ \\
2 & Panjang & $10300 \mathrm{~mm}$ \\
3 & Shell / Head Thickness & $25 \mathrm{~mm} / 12 \mathrm{~mm}$ \\
4 & Joint Efficiency & 1 \\
5 & Tekanan & $0.21 \mathrm{MPa}$ \\
6 & Temperature desain internal & $60^{\circ} \mathrm{C}$ \\
7 & Temperature desain eksternal & $25^{\circ} \mathrm{C}$ \\
\hline
\end{tabular}

Tabel 2.2 Variabel pengujian

\begin{tabular}{cc}
\hline No & Jarak saddle ke tangent \\
\hline 1 & $250 \mathrm{~mm}$ \\
2 & $450 \mathrm{~mm}$ \\
3 & $650 \mathrm{~mm}$ \\
4 & $850 \mathrm{~mm}$ \\
5 & $1050 \mathrm{~mm}$ \\
6 & $1250 \mathrm{~mm}$ \\
\hline
\end{tabular}

Tabel 2.3 Spesifikasi material SA 516 Gr 70

\begin{tabular}{cccc}
\hline Material & Modulus Elastisitas & Poison Ratio & Yield Strength \\
\hline SA 516 Gr. 70 & $192 \mathrm{GPa}$ & 0,30 & $260 \mathrm{MPa}$ \\
\hline
\end{tabular}

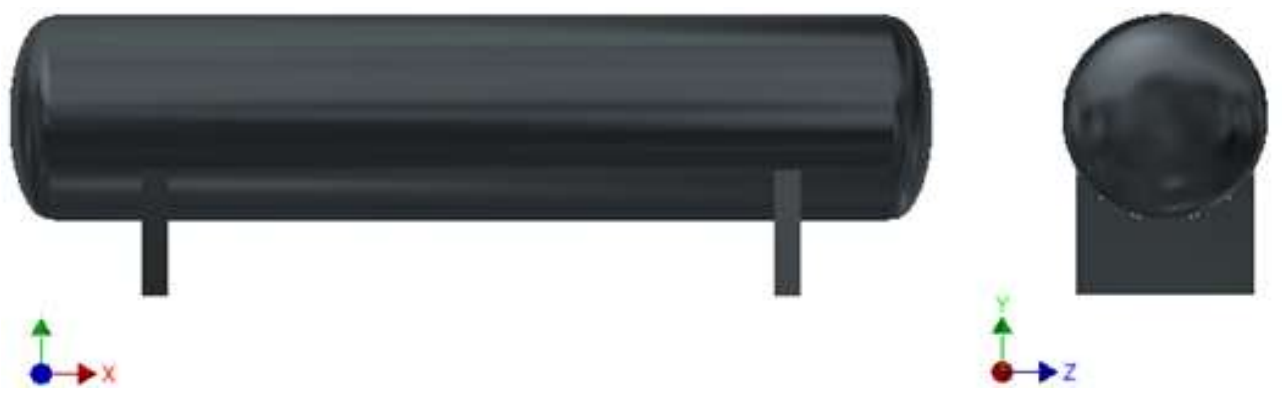

Gambar 2.1 Geometry bejana tekan dengan jarak saddle ke tangent 1250 mm 

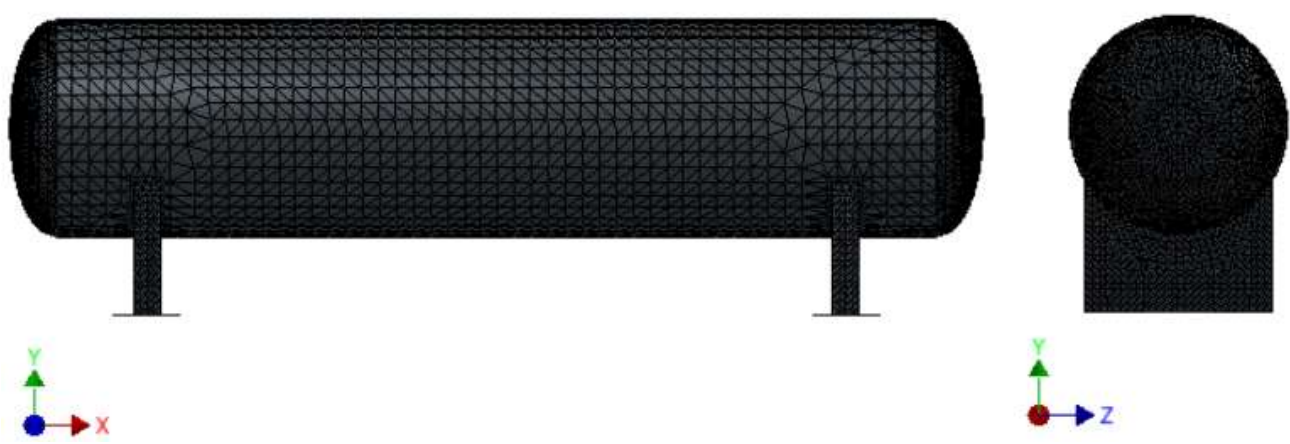

Gambar 2.2 Hasil mesh geometry bejana tekan dengan jarak saddle ke tangent $1250 \mathrm{~mm}$

\section{Hasil dan Pembahasan}

Penelitian ini menghasilkan data distribusi tegangan dan distribusi displacement yang terjadi pada struktur bejana tekan tersebut. Hasil distribusi tegangan tersaji pada Tabel 3.1, sedangkan distribusi displacement tersaji pada Tabel 3.2. Distribusi tegangan dan displacement yang terjadi pada struktur bejana tekan tersebut didapatkan dari simulasi analisis tegangan menggunkan Software Autodesk Inventor.

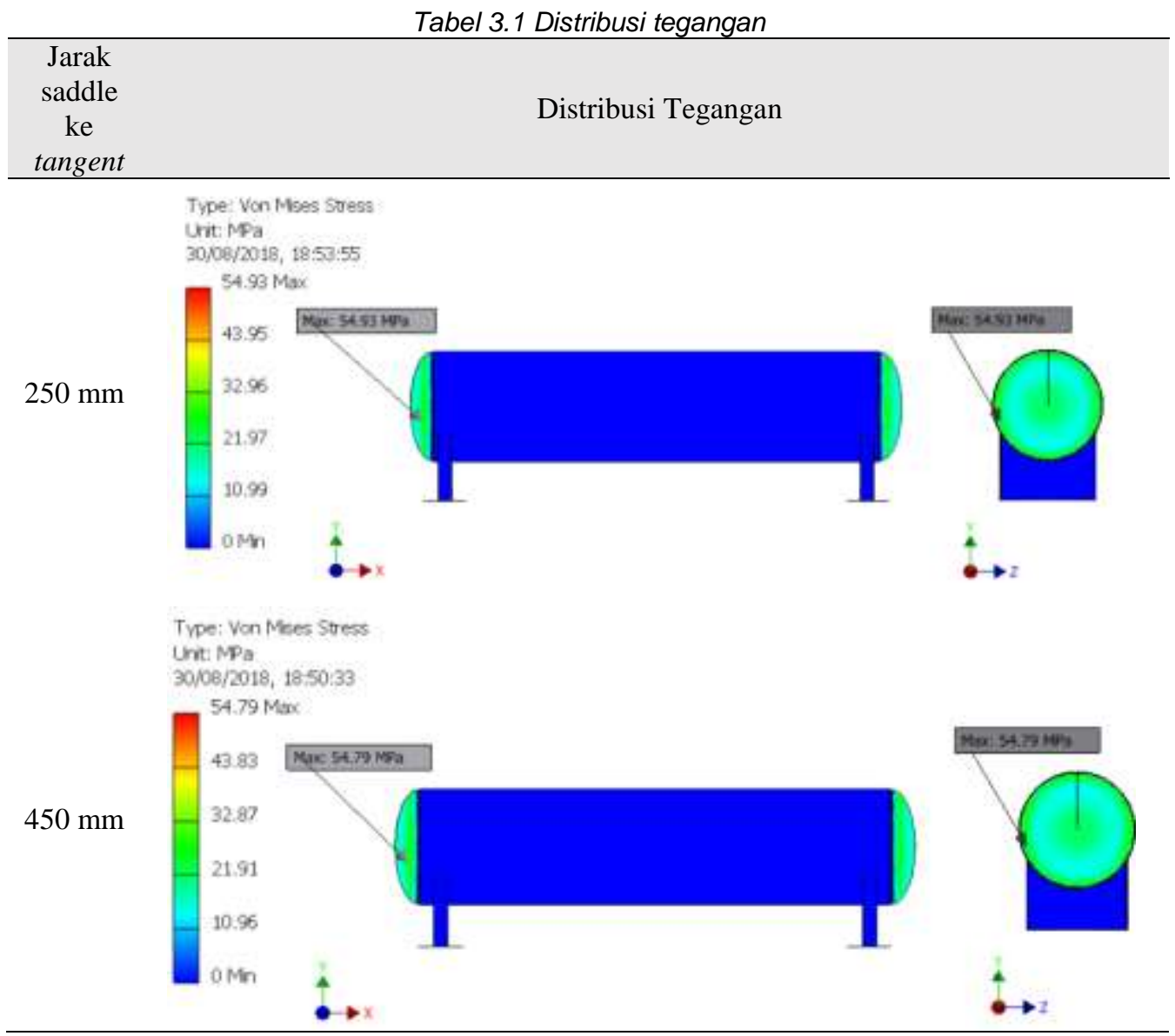




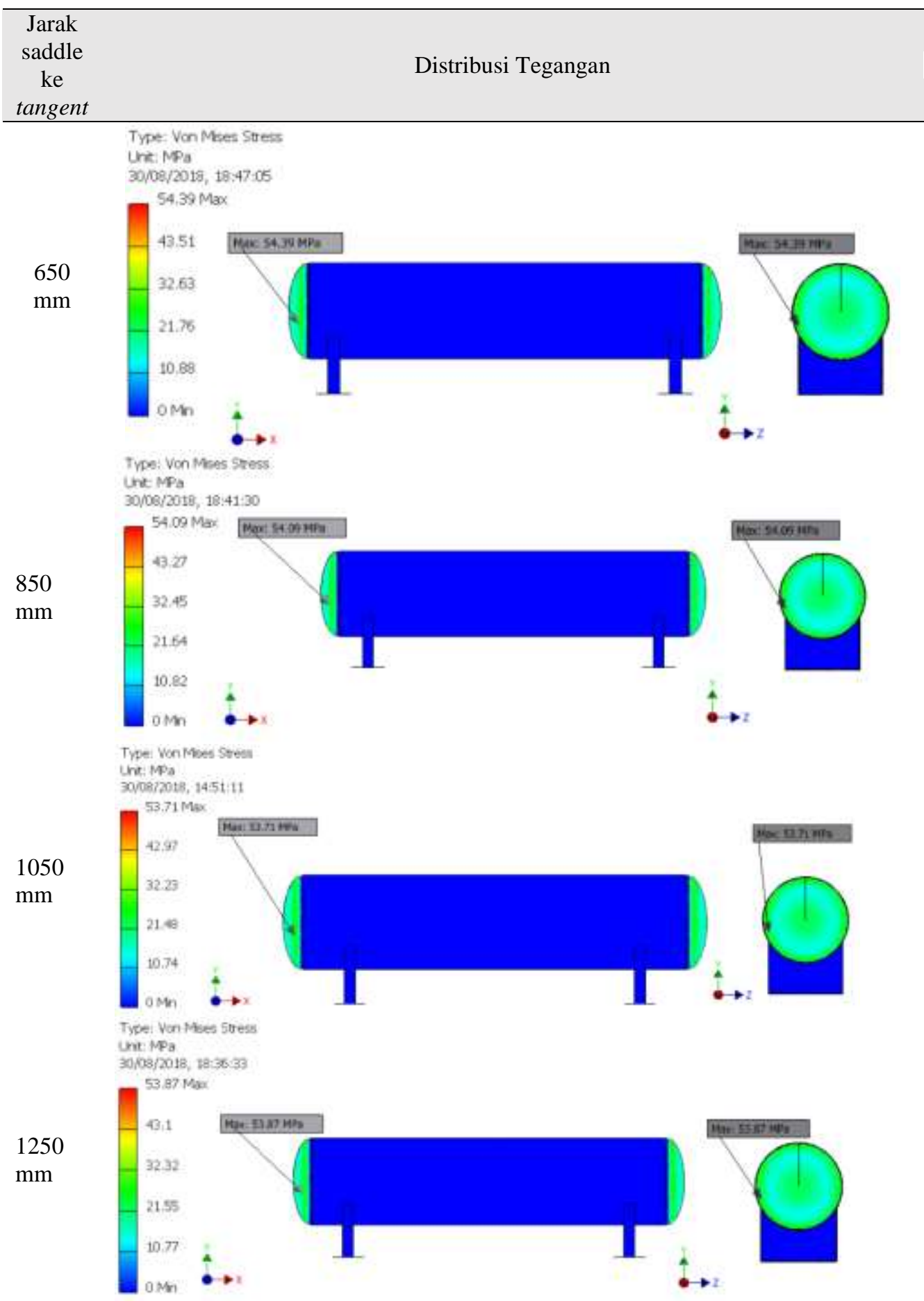




\section{$\overline{\mathbf{\Pi}}$ Teknik}

Krisdiyanto

許

Tabel 3.2 Distribusi displacement

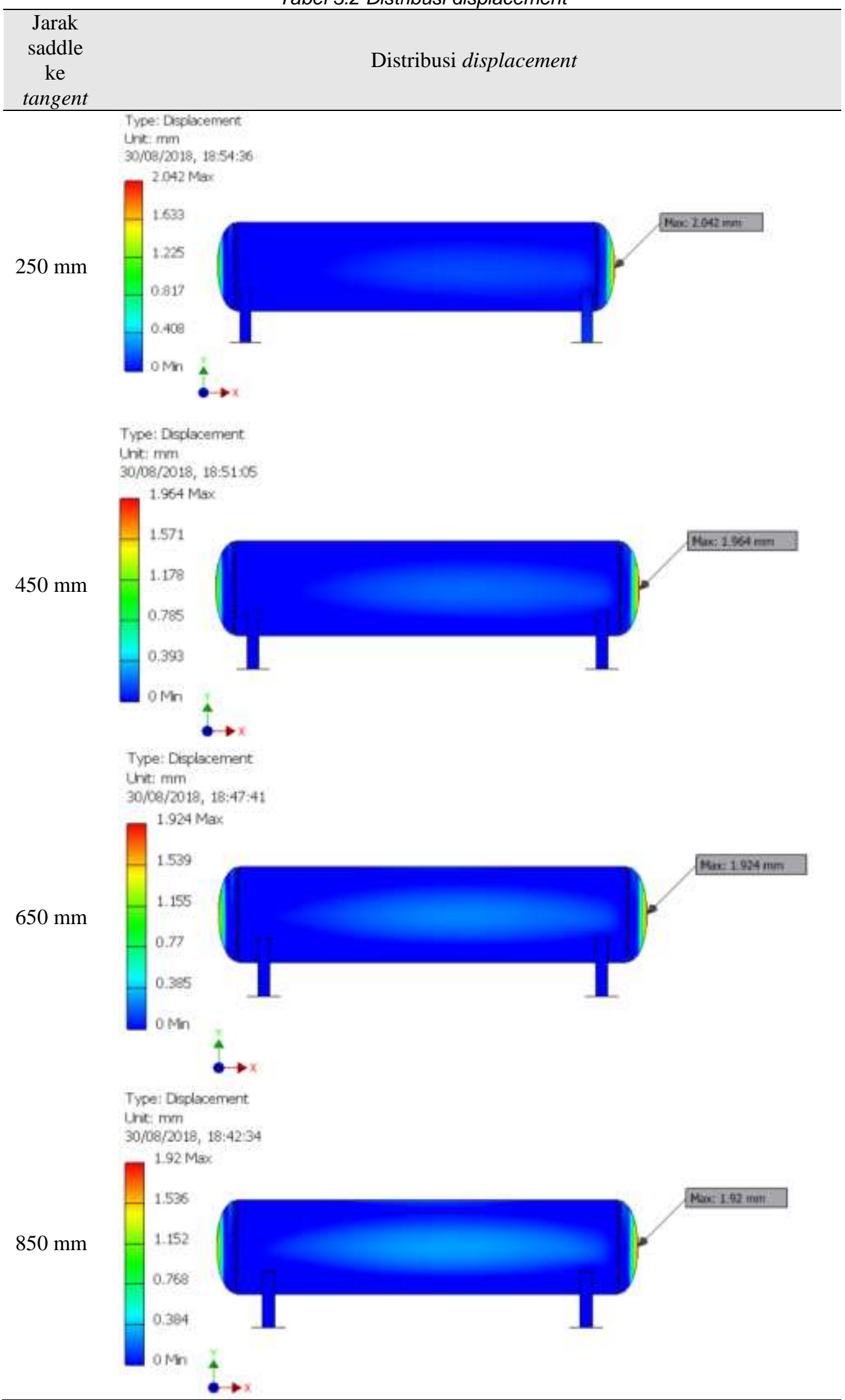




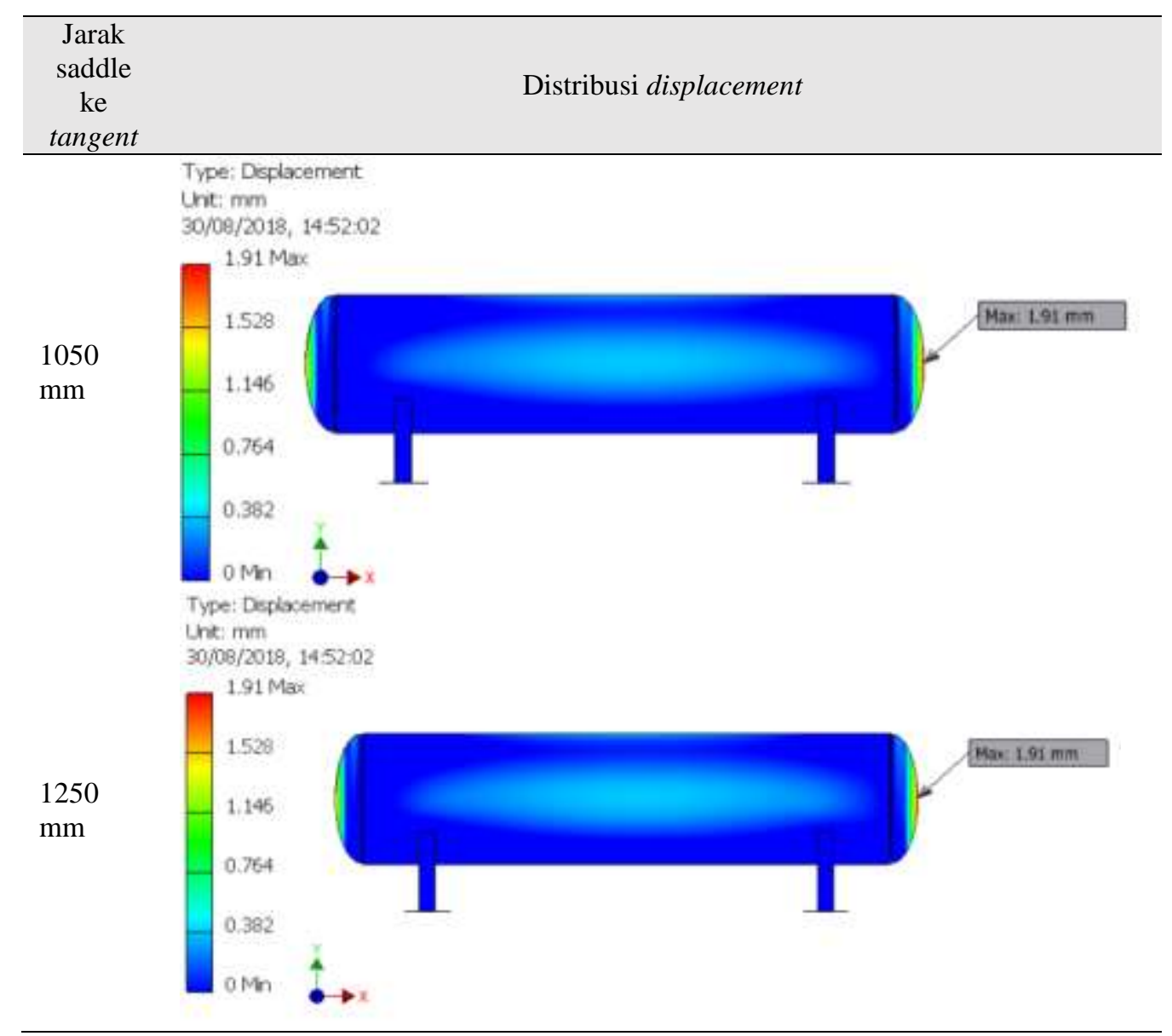

Tabel 3.1 menunjukan distribusi tegangan setiap struktur yang disimulasikan, sedangkan nilai displacement yang terjadi tersaji pada Tabel 3.2. Nilai tegangan masksimum dan displacement maksimum yang terjadi disusun ke dalam Tabel 3.3 sehingga bisa dibuat grafik yang menunjukan pengaruh dari jarak saddle dengan tangent pada bejana tekan terhadap tegangan maksium dan displacement yang terjadi. Grafik yang menunjukan pengaruh jarak saddle dan tangent terhadap tegangan maksimum yang terjadi tersaji pada Gambar 3.1 dan Grafik yang menunjukan pengaruh jarak saddle dan tangent terhadap displacement maksimum tersaji pada Gambar 3.2.

Tabel 3.3 Tegangan maksimum dan displacement maksimum

\begin{tabular}{ccc}
\hline $\begin{array}{c}\text { Jarak saddle dan } \\
\text { tangent }(\mathrm{mm})\end{array}$ & $\begin{array}{c}\text { Tegangan Maksimum } \\
(\mathrm{Mpa})\end{array}$ & $\begin{array}{c}\text { Displacement } \\
\text { maksimum }(\mathrm{mm})\end{array}$ \\
\hline 250 & 54.90 & 2.042 \\
450 & 54.79 & 1.964 \\
650 & 54.39 & 1.924 \\
850 & 54.09 & 1.920 \\
1050 & 53.87 & 1.919 \\
1250 & 53.71 & 1.910 \\
\hline
\end{tabular}




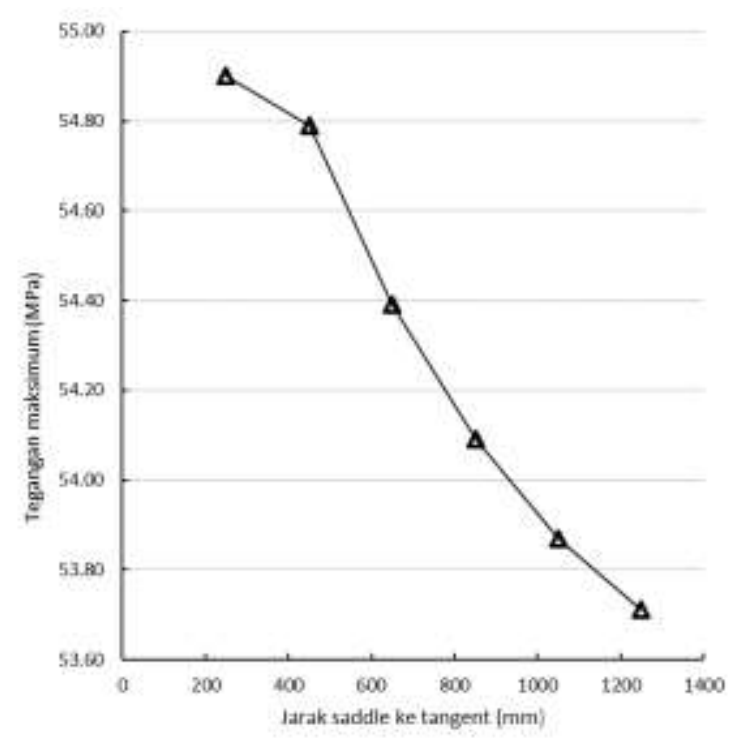

Gambar 3.1 Grafik pengaruh jarak saddle dan tangent terhadap tegangan maksimum

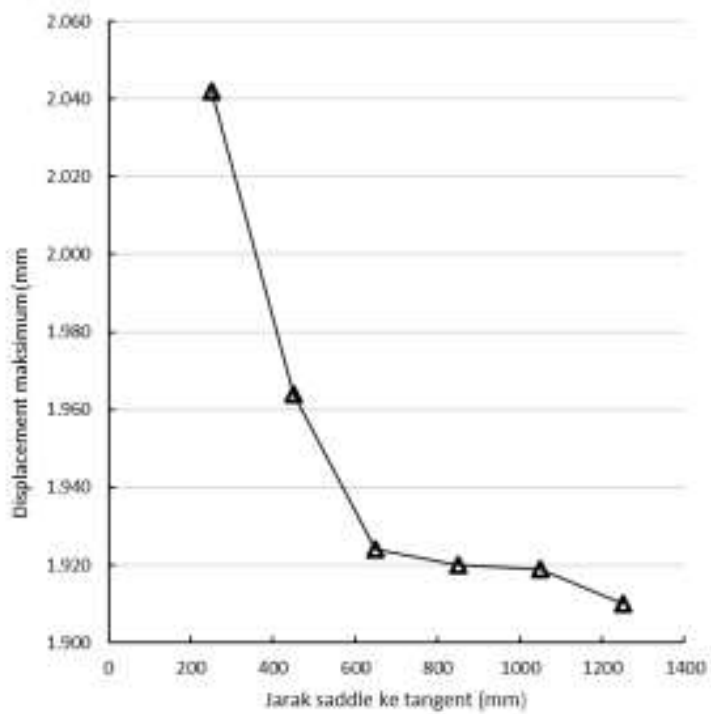

Gambar 3.2 Grafik pengaruh jarak saddle dan tangent terhadap displacement maksimum

Grafik yang tersaji pada Gambar 3.1 menunjukan bahwa jarak saddle dan tangent semakin besar maka tegangan maksimum yang terjadi akan semakin kecil. Jarak saddle dan tangent juga mempengaruhi displacement yang terjadi pada bejana tekan. Hal tersebut dapat dilihat pada Gambar 3.2 bahwa semakin besar jarak saddle dan tangent maka semakin kecil displacement yang terjadi.

\section{KeSIMPULAN}

Tegagan dan displacement terbesar pada penelitian ini sebesar 54,90 MPa dan 2,042 $\mathrm{mm}$. Nilai tegangan dan displacement terbesar terjadi pada variasi jarak saddle dan tangent sebesar $250 \mathrm{~mm}$. Tegangan dan displacement terkecil pada penelitian ini sebesar 53,71 $\mathrm{MPa}$ dan $1,910 \mathrm{~mm}$. Nilai tersebut terjadi pada variasi jarak saddle dan tangent sebesar $1250 \mathrm{~mm}$. Data yang dihasilkan pada simulasi pengaruh jarak saddle dan tangent pada bejana tekan dalam penelitian ini menunjukan bahwa nilai tegangan dan displacement terkecil yang dihasilkan terjadi pada bejana tekan dengan jarak saddle dan tangent sebesar $1250 \mathrm{~mm}$ atau setengah dari inside diameter bejana tekan. 


\section{Daftar Pustaka}

[1] Kumar, V., Kumar, N., Angra, S., dan Sharma, P. Design of Saddle Support for Horizontal Pressure Vessel, International Journal of Mechanical, Aerospace, Industrial and Mechatronics Engineering. 2014; 8: 1797-1801.

[2] Seng, O. L. Analysis of Twin-Saddle-Supported Vessel Subjected to Non-Symmetric Loadings, Int. J. Pres Ves \& Piping. 1988; 35: 423-437.

[3] Yang, L., Weinberger, C., dan Shah, Y. T. Finite Element Analysis on Horizontal Vessels with Saddle Support, Computers \& Structures. 1994; 52: 387-395.

[4] Zick, L. P. Stresses in Large Horizontal Cylindrical Pressure Vessels on Two Saddle Support, The Welding Journal Research Supplement. 1951: 959-970.

[5] Zore, A., dan Qaimi, M. G. Design and Optimization of Saddle for Horizontal Pressure Vessel, International Engineering Research Journal. 2015; 2: 4201-4204. 